\title{
Investigations of co-localization of albumin, fibrinogen and some complement components on the vascular surfaces
}

\author{
ALEKSANDER JEREMI WASIUTYŃSKI, TOMASZ ILCZUK, EWA BARBARA WILCZEK
}

Department of Pathology, Medical University of Warsaw, Poland

\begin{abstract}
Albumin and fibrinogen, two independent plasma proteins are able to produce a relatively stable complex which is present on the surface of multiple cells. Existence of such structure was reported in the 1960s and 1970s by Brzosko and Nowostawski, Groniowski, and confirmed in vitro by Lipinski in 1995. It was believed to provide protection against immunocompetent cells. In 2002, we showed the presence of a structural lining composed of albumin and fibrinogen on the surface of placental villi. Immunohistochemistry and immunoflurescence confirmed presence of this complex on the endothelial surface. We also found complement proteins such as C1q, C4d, C9, and double immunofluorescence confirmed the presence of this complex and complement components in the aortic vasa vasorum. Both membrane-bound (CD46, CD55, CD59) and soluble (H factor) complement inhibitors were present.

Studies indicate that this lining is composed of plasma proteins and complement components and since it is present on the endothelial surface, it can play a role of a natural immune barrier protecting against pathological processes in the blood vessels.
\end{abstract}

Key words: albumin, fibrinogen, complement system, complement inhibitors.

(Centr Eur J Immunol 2013; 38 (3): 283-288)

\section{Introduction}

Two independent plasma proteins - albumin and fibrinogen, are capable of forming a complex which is present on the surface of multiple cells and has a relatively stable structure. Existence of such structure was reported in the 1960s and 1970s by Brzosko and Nowosławski, Groniowski (who used meta-labeling and demonstrated that glycosaminoglycans could be an integral part of the plasma membrane), and confirmed in vitro by Lipiński in 1995 [1-3]. Other research reports of studies of the blood vessel wall and endothelium discussed predominantly biochemical and physiological-pathological processes occurring in these structures, but did not refer to their morphology [4].

To understand the problem discussed in this study, we must first review components of the investigated structure and processes occurring on the vascular surface.

\begin{abstract}
Albumin is a protein produced by both hepatocytes and Browicz-Kupffer cells in the liver. It plays an essential role in maintaining oncotic pressure required for maintenance of the normal ratio of water in the blood and water in the tissue fluids. Albumin also buffers $\mathrm{pH}$, transports certain hormones, drugs, fatty acids and bile pigments as well as binds and transports carbon dioxide.

Fibrinogen $(\mathrm{Fb}$ - clotting factor $\mathrm{I})$ is a plasma protein synthesized in the liver and by megakaryocytes. It is located in granules of mature blood platelets and is released to the blood along with other proteins during the secondary phase of blood platelet aggregation. A characteristic feature of fibrinogen is its susceptibility to action of various proteases and in particular to enzymes of clotting and fibrinolysis system: thrombin and plasmin. As a result of thrombin action on fibrinogen, fibrin peptides $\mathrm{A}$ and $\mathrm{B}$ and fibrin monomers (fibrin) are formed, which are involved in the final phase of the blood clotting process.
\end{abstract}

Correspondence: Tomasz Ilczuk, Department of Pathology, Medical University of Warsaw, Chałubińskiego 5, 02-004 Warsaw, Poland, tel. 791584 498, e-mail: tomasz.ilczuk@wum.edu.pl 
The complement system is a set of several proteins that occur in plasma as well as in other body fluids along with their associated numerous receptors and regulatory proteins. The complement plays an important role in the congenital, humoral mechanism of non-specific immune response, but is also closely associated with some mechanisms of specific immune response. Complement activation involves a series of enzymatic and non-enzymatic cascade reactions. This means that each activated complement component activates another component. Activation of complement results in formation of two important enzymes: C3 and C5 convertases that potently enhance its effects. However, irrespectively of the method of its activation, final stages of all these reactions are identical and result in formation of the membrane attacking complex (MAC) that is composed of $\mathrm{C} 5 \mathrm{~b}$, C6, C7, C8 and polymeric C9 (Fig. 1). The complement system requires efficient regulation occurring at multiple stages of its activation. This notion is supported by examples of pathologies caused by its excessive activation. There are several regulatory proteins, both in the plasma and on the surface of plasma membranes that control complement activity. These are inactivating factors that usually act to shorten already short half-life of C3 and C5 convertases. Factor $\mathrm{H}$ that binds $\mathrm{C} 3 \mathrm{~b}$ and facilitates inhibition of $\mathrm{C} 3$ convertase by factor I is one of the plasma factors. Factors that are present on cells are responsible for inactivation of specific complement components and include: membrane protein cofactor $(C D 46)$ - binding $\mathrm{C} 3 \mathrm{~b}$ and $\mathrm{C} 4 \mathrm{~b}$ is present essentially on all mononuclear cells in the body; decay accelerating factor (CD55) - dramatically shortens halflife of convertases; homologous restriction factor (CD59) - binds C8 and C9, inhibiting MAC formation [5-7].

The aim of this study was to demonstrate presence of albumin, fibrinogen, complement proteins and its inhibitors on vascular surfaces.

\section{Material and methods}

Renal arteries and aortic specimens collected at autopsy were the tissue material used in this study. Specimens were fixed in $4 \%$ buffered formalin, embedded in paraffin blocks and then cut into $4 \mu \mathrm{m}$ thick sections and mounted on glass slides. Paraffin sections underwent routine hematoxylin and eosin staining, Mallory-Azan triple staining as well as immunohistochemistry and immunofluorescence. The following antibodies were used to detect complement components and its inhibitors in the examined tissue material:

- Mouse Anti Human CD46 (AbD Serotec, UK),

- Mouse Anti Human CD55 (AbD Serotec, UK),

- Mouse Anti Human CD59 (AbD Serotec, UK),

- Monoclonal Antibody to Human Factor H (Quidel, USA),

site of action of complement inhibitors
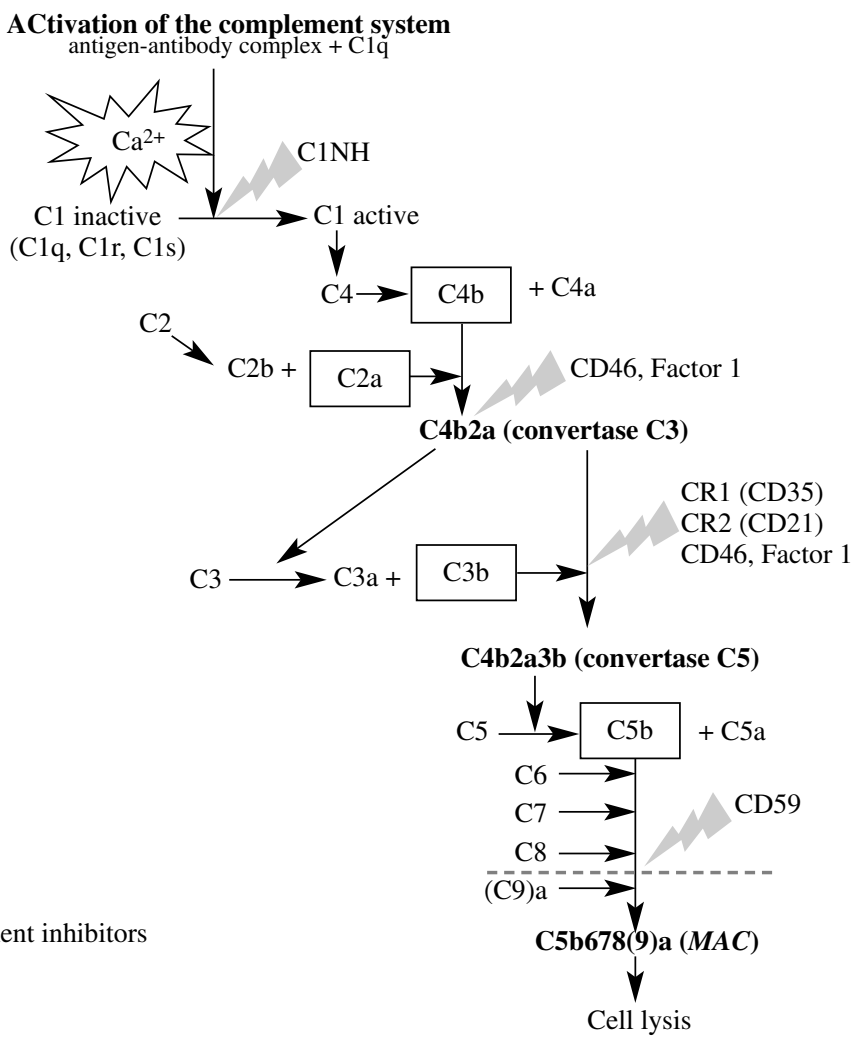

Fig. 1. Activation of the complement system 
A

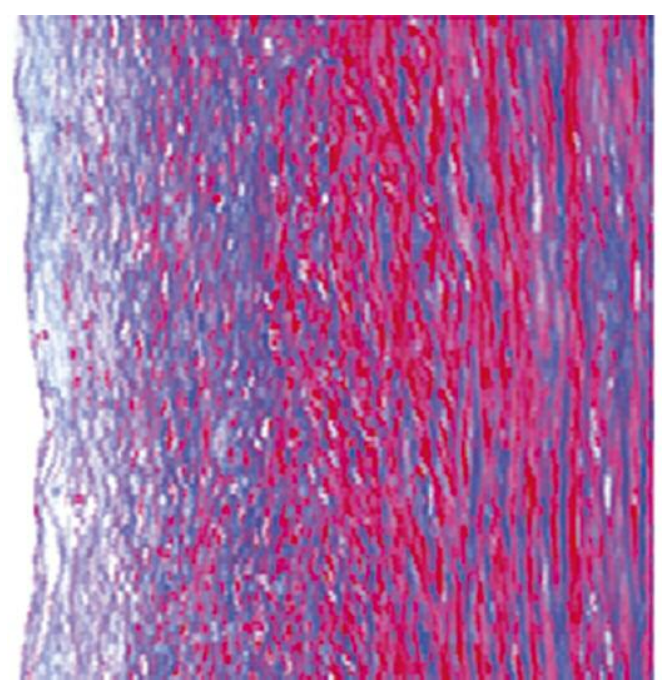

B

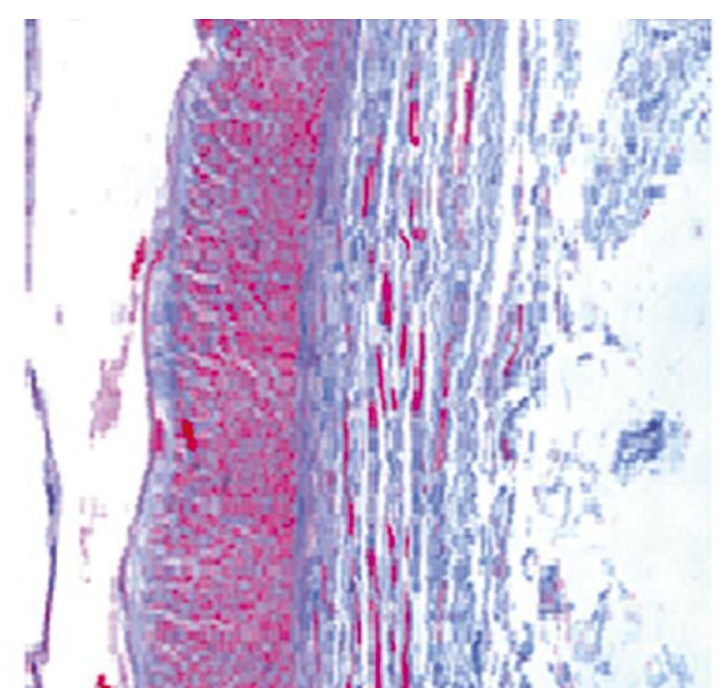

Fig. 2. Mallory-Azan triple staining (azocarmine, orange G, aniline blue): A) aorta, B) renal artery

- Anti Human C4d Antibody (Oxford Biosystems, UK),

- Human Complement Component C9 (Novocastra, UK),

- Polyclonal Rabbit Anti-Human C1q complement (Dako, Denmark),

- Polyclonal Rabbit Anti-albumin and Anti-fibrinogen (Dako, Denmark).

Immunohistochemistry reaction was run in the following manner: routinely deparaffinized sections were treated with $3 \%$ hydrogen peroxide to quench endogenous peroxidase and 5\% donkey serum to block non-specific antibody binding sites (Jackson ImmunoResearch, USA). Then, primary antibody solutions were added to the sections, incubated in the humid chamber overnight at $+4^{\circ} \mathrm{C}$. Secondary antibodies conjugated with peroxidase, ImmPress Reagent Kit Anti-Mouse/Rabbit IgG (Vector Laboratories, USA), were used to detect the primary antibodies, while anti-goat antibody conjugated with peroxidase (Jackson ImmunoResearch, USA) was used to detect goat antibodies. 3-3' diaminobenzidine (Dako, Denmark) was used as a chromogen. Subsequently, the sections were stained with hematoxylin, dehydrated and closed as slides.

Secondary fluorochrome-conjugated donkey anti-goat antibodies with Alexa 555 (Jackson ImmunoResearch, USA) and donkey anti-rabbit antibodies with Alexa 488 (Jackson ImmunoResearch, USA) were used for immunofluorescence studies. After completion of staining, the sections were stained with Hoechst stain to visualize cellular nuclei and closed in Vectashield medium (Vector Laboratories, USA). Furthermore, rhodamine-labeled phalloidin was used to stain the cells. Results were analyzed in the confocal microscope Leica TCS SP5 (Leica Microsystems, Germany) and fluorescence microscope Nikon Eclipse 80i (Nikon, Japan).

\section{Results}

Mallory-Azan triple staining was used to assess structures of the investigated blood cells (Fig. 2). Endothelial cells and loose connective tissue located underneath them, containing smooth muscle cells and few fibroblasts, stained red while elastic fibers and plaques as well as collagen fibers stained blue.

Immunochemistry studies demonstrated the complement components $\mathrm{C} 1 \mathrm{q}, \mathrm{C} 4 \mathrm{~d}$, and $\mathrm{C} 9$ both in the renal artery and in the aorta. The most abundant was $\mathrm{C} 1 \mathrm{q}$, located throughout the vascular wall (Fig. 3). C4d in the aortic wall was predominantly located in the external part, while surrounded by a small vessel (vasa vasorum) in the artery. The complement component C9 was most commonly located on the surface of the whole aortic section, while was less abundant in the artery. Staining for factor $\mathrm{H}$ demonstrated abundance of this inhibitor in the external wall of the artery.

Double immunofluorescence reactions and analysis of its results in the confocal microscope demonstrated co-localization of albumin and fibrinogen on the surface of aorta and renal arteries (Fig. 4).

Immunofluorescence staining for complement components and complement system inhibitors demonstrated more abundant localization of CD59 and factor $\mathrm{H}$ on the luminal surface both in the renal artery and in the aorta. The C4d complement component was localized throughout the vessel wall (Fig. 5).

Further immunofluorescence staining demonstrated complement components as well as complement regulators located around immunopositive structures for albumin and fibrinogen (Fig. 6). The figures below present outcomes of these reactions. 

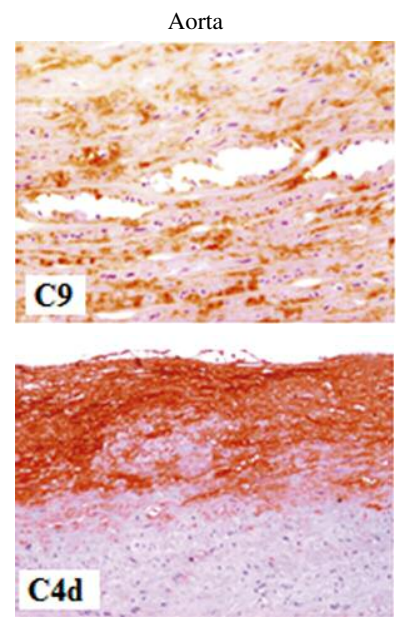
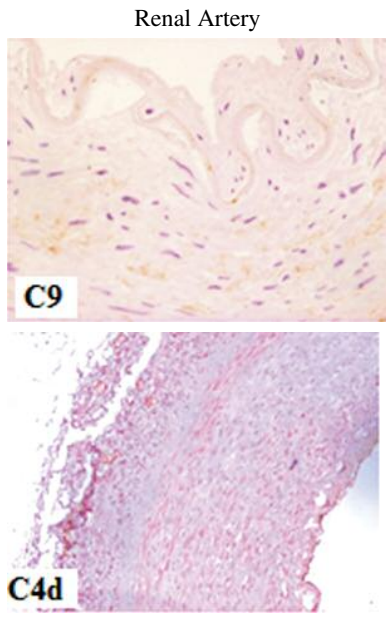

Renal Artery
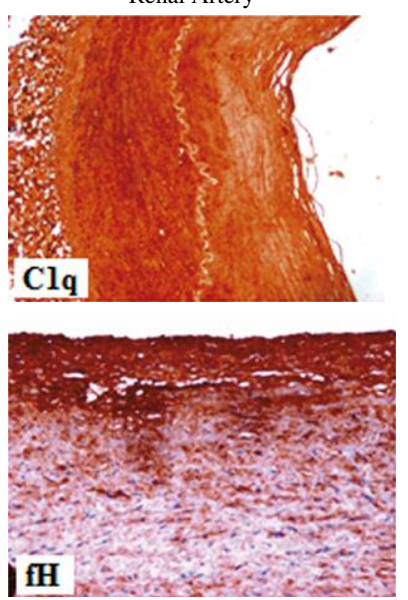

Fig. 3. Immunohistochemistry results - proteins of the complement system and its inhibitors in the aorta and renal arteries

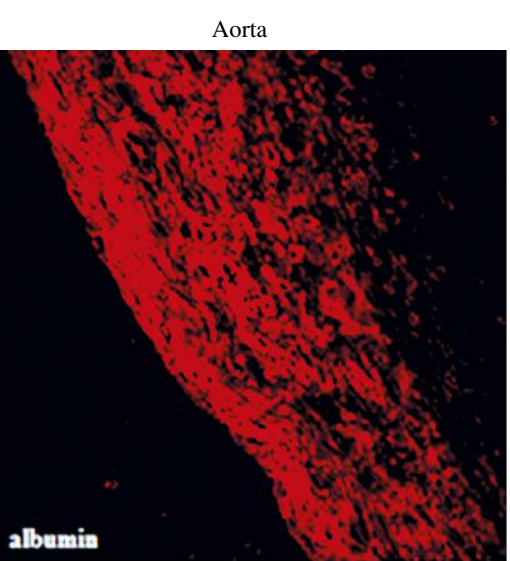

Renal Artery

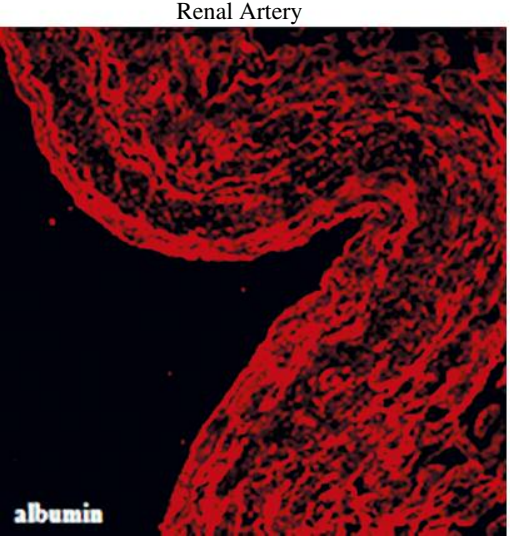

Aorta

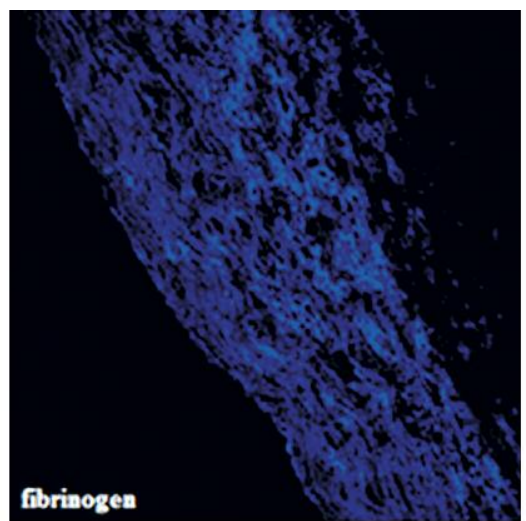

Renal Artery

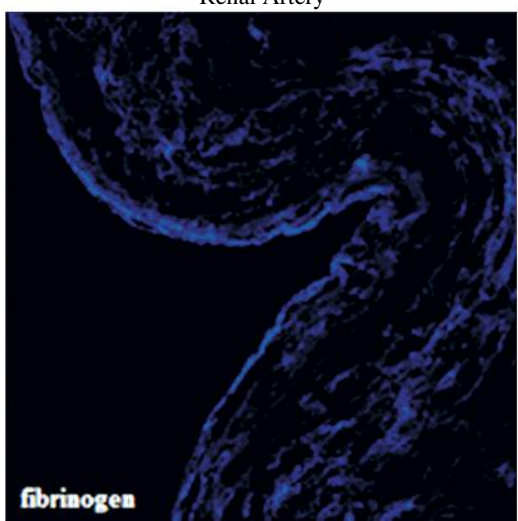

Aorta

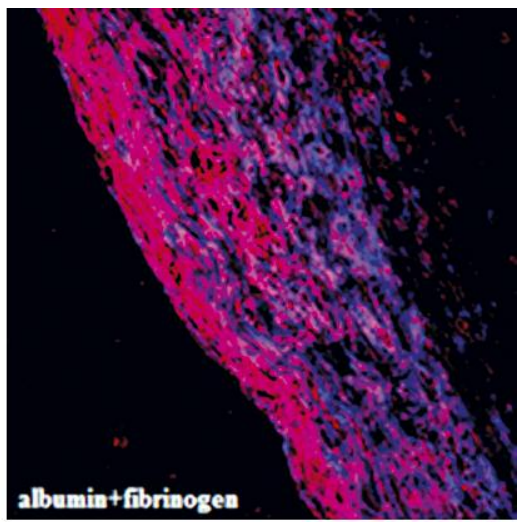

Renal Artery

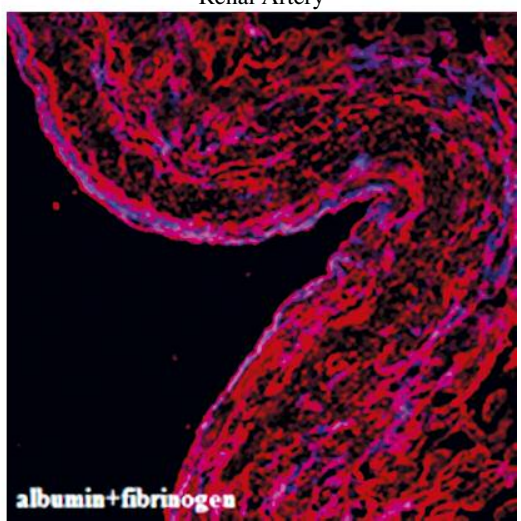

Fig. 4. Immunofluorescence staining for albumin and fibrinogen

\section{Discussion}

Investigations presented in our paper demonstrated presence of structures in the investigated vessels where albumin, fibrinogen and the complement components are colocalized. In a light microscope, immunohistochemistry reaction for albumin and fibrinogen was difficult to inter- pret since it only demonstrated common presence of these proteins in the tissues. Positive immunohistochemistry reaction was found in cells, intercellular space as well as vascular lumen. Therefore, assessment in the light microscope could not be conclusive [8]. On the other hand, studies using the confocal microscope demonstrated a precise subcellular location of the investigated proteins with a higher reso- 
Aorta

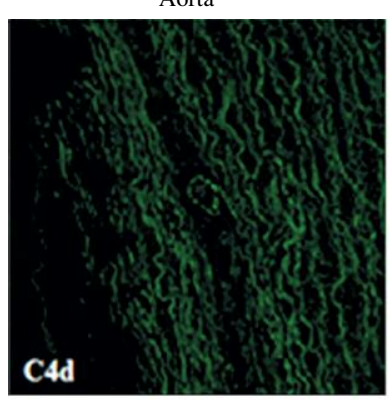

Renal Artery

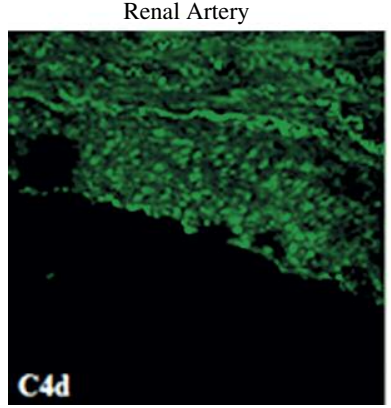

Aorta

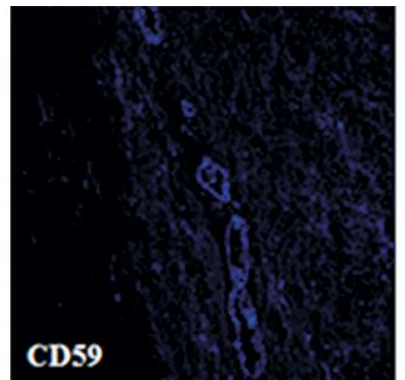

Renal Artery

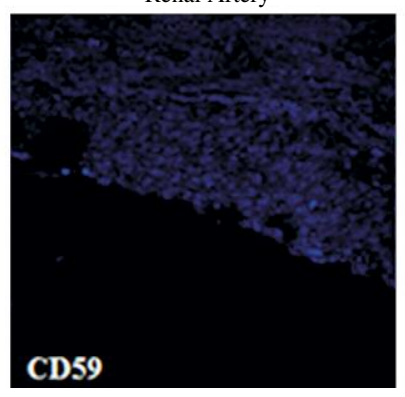

Aorta

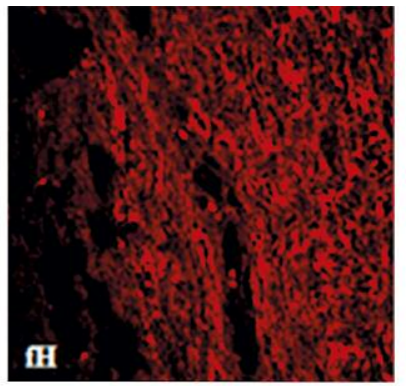

Renal Artery

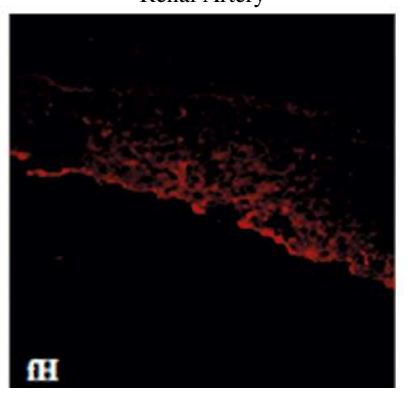

Aorta

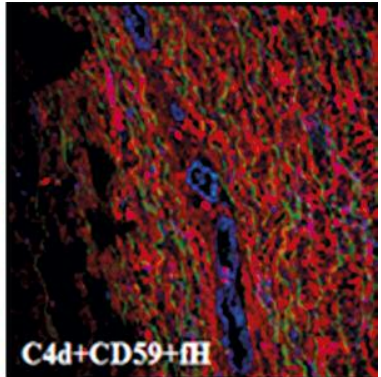

Renal Artery

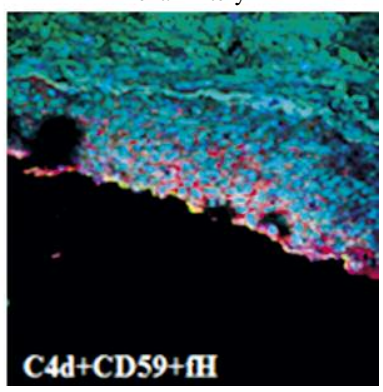

Fig. 5. Immunofluorescence staining for the complement proteins and its inhibitors

Aorta

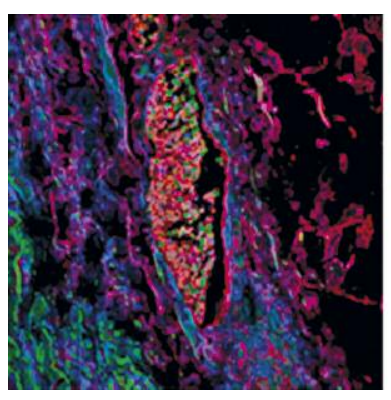

口albumin
Renal Artery

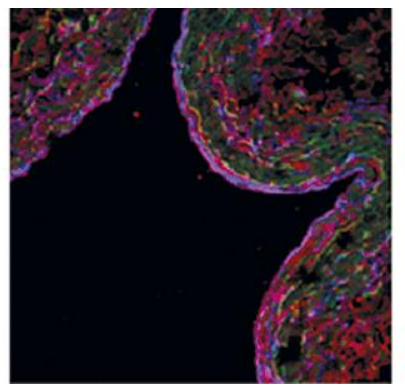

C9
Aorta

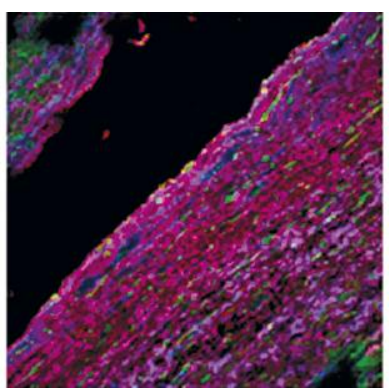

albumin
Renal Artery

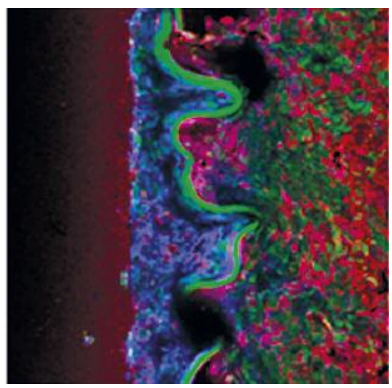

fibrinogen

CD59

Fig. 6. Immunofluorescence staining for the complex made of albumin, fibrinogen, proteins and complement inhibitors

lution. Available literature lacks detailed studies of this complex and its role in the pathogenesis of cardiovascular disease. Only few papers mention this problem relatively briefly [9-12].

Following analysis of available scientific literature [1316] and results of studies performed by e.g. Brzosko and Nowosławski which demonstrated presence of albumin and fibrinogen in spaces between placental villi, we decided to investigate the pattern of occurrence of these proteins using immunofluorescence techniques utilizing a confocal microscope. Villi were proven to have a thin albumin and fibrinogen deposit on their surface. FRET ${ }^{1}$ technique also confirmed presence of this complex. Assessed distance of deposits of the tested plasma proteins on the surface of placental villi confirmed that they form complexes. Deposits were also found on the surface of villi blood vessels. We also found that a complex formed of albumin and fibrinogen was a definite morphological structure on the surface of syncytiotrophoblast. Presence of the complement inhibitors in this complex raises a question of its role as a natural barrier with relevance to the immune system $[17,18]$.

In this study we attempted to demonstrate presence of the tested complex and elucidate its role on the endothelial surface. Basing on our immunohistochemistry and immunofluorescence reactions and analysis of their results we demonstrated presence of a complex composed of plasma

${ }^{1}$ Förster Resonance Energy Transfer, mechanism of energy transfer between two chromophobes, an investigative technique that demonstrated co-occurrence of proteins, if they are close enough together 
proteins (albumin, fibrinogen) and the complement (C1q, $\mathrm{C} 4 \mathrm{~d}$, and C9), and co-localization of membrane-bound (CD46, CD55, CD59) and soluble (factor H) complement inhibitors. Lining that is present on the endothelial surface can form a natural barrier of immunological relevance.

\section{Summary}

Our results clearly indicate the common presence of a complex composed of albumin, fibrinogen and complement proteins on the vascular surface. We found that their location is identical in all cases. Thus, we found that the investigated complex is a morphological structure. However, its role as a natural barrier of relevance to the immune system, protecting against pathogenic changes occurring in the blood vessels, currently is unexplained. Therefore, studies aimed at obtaining answers to the presented problem, should be continued and expanded using newest research techniques in an attempt to provide more effective fight against diseases that current medicine is largely unable to cure.

\section{The authors declare no conflict of interests.}

\section{References}

1. Groniowski J, Kruś S (1991): Podstawy patomorfologii. PZWL, Warszawa.

2. Lipinski B (1995): In vitro preparation and partial characterization of a novel complex of human fibrinogen with albumin. J Protein Chem 14: 259-262.

3. Lipinski B, Egyud LG (2000): Resistance of cancer cells to immune recognition and killing. Med Hypotheses 54: 456-460.

4. Kumar V, Cotran RS, Robbins SL (2005): Basic Pathology. Wydanie I polskie pod redakcją Włodzimierza T. Olszewskiego. Wydawnictwo Medyczne Urban \& Partner, Wrocław, 374-453.

5. Gołąb J, Jakóbisiak M, Lasek W, et al. (2011): Immunologia. Wydawnictwo Naukowe PWN, Warszawa; 66-77.

6. Chapel H, Haeney M, Misbah S (2009): Immunologia kliniczna, Wydanie I polskie pod redakcją Grzegorza Senatorskiego, Wydawnictwo Czelej, Lublin.

7. ter Weeme M, Vonk AB, Kupreishvili K, et al. (2010): Activated complement ismore extensively present in diseased aortic valves than naturally occurring complement inhibitors: a sign of ongoing inflammation. Eur J Clin Invest 40: 4-10.

8. Frank HG, Malekzadeh F, Kertschanska S, et al. (1994): Immunohistochemistry of two different types of placental fibrinoid. Acta Anat (Basel) 150: 55-68.

9. Wojnicz D, Jankowski S (2002): Rola białkowych glikoprotein CD46, CD55, CD59 w ochronie komórek przed licznym działaniem dopełniacza. Pods Hig Dośw 603-616.

10. Schepers A, de Vries MR, van Leuven CJ, et al. (2006): Inhibition of Complement Component C3 Reduces Vein Graft Atherosclerosis in Apolipoprotein E3 -Leiden Transgenic Mice. Circulation 114: 2831-2838.

11. Rus H, Niculescu F (2003): Association of complement inhibitors with connective tissue matrix in atherosclerotic lesions. Arterioscler Thromb Vasc Biol 23: 1478.
12. Klaska I, Nowak JZ (2007): The role of complement in physiology and pathology. Postepy Hig Med Dosw (Online) 61: 167-177.

13. Choi-Miura NH, Sakamoto T, Ohtaki S, et al. (1993): Elevated complement activities of sera from patients with high density lipoprotein deficiency (Tangier disease): the presence of normal level of clusterin and the possible implication in the atherosclerosis. Clin Exp Immunol 93: 242-247.

14. Yasojima K, Schwab C, McGeer EG, et al. (2001): Complement components, but not complement inhibitors, are upregulated in atherosclerotic plaques. Arterioscler Thromb Vasc Biol 21: 1214-1219.

15. Tornehave D, Hougaard DM, Larsson L (2000): Microwaving for double indirect immunofluorescence with primary antibodies from the same species and for staining of mouse tissues with mouse monoclonal antibodies. Histochem Cell Biol 113: 19-23.

16. Fishelson Z, Attali G, Mevorach D (2001): Complement and apoptosis. Mol Immunol 38: 207-219.

17. Wasiutyński A, Wilczyński GM, Morton M, et al. (2002): Fibrinogen/fibrin and albumin colocalize on the surface of placental villi - a novel element of feto-maternal barier? Annals of Diagnostic Paediatric Pathology 6: 123-127.

18. Sharma N, Hewett J, Ozelius LJ, et al. (2001): A close association of torsinA and alpha-synuclein in Lewy bodies: a fluorescence resonance energy transfer study. Am J Pathol 159: 339-344. 